\title{
Conflitos familiares e desempenho acadêmico numa visão humanis- ta: relato de uma experiência
}

\author{
Family conflict and academic performance in a humanistic vision: an experience report \\ Fátima Niemeyer Rocha, Suely Cristina de Souza Fernandes Crahim.
}

\begin{abstract}
Resumo
O texto apresenta o relato da experiência de atuação psicoterapêutica e psicopedagógica no Núcleo de Apoio Psicopedagógico de uma instituição de ensino superior. Foi possível observar que o universo relacional que envolve a dinâmica familiar de jovens universitários pode exercer uma forte influência negativa no seu desempenho acadêmico, provocando dificuldades e insucessos. Alguns dos fatores produtores de conflitos familiares, relatados pelos alunos, foram: rivalidade entre os irmãos, rejeição clara ou velada do filho pelos pais, ciúme dos pais em relação ao filho, ressentimento dos pais quanto às realizações do filho, exigência excessiva dos pais quanto ao sucesso acadêmico do filho, superproteção do filho, exagerado sentimento de responsabilidade familiar do filho e solidão no período de adaptação a vida acadêmica. Numa visão humanista, as atuações tanto psicológica quanto psicopedagógica objetivaram proporcionar ao aluno um suporte facilitador da aquisição de uma competência para aprender. Palavras-Chave: Conflitos familiares. Desempenho acadêmico. Psicologia. Psicopedagogia. Humanismo.
\end{abstract}

Crahim SCSF Conflitos familiares e desempenho acadêmico numa visão humanista: Relato de uma experiência. Revista Mosaico. 2014 Jul./Dez.; $05 \quad$ (2): 15-17.

\begin{abstract}
The text presents the report on the psychotherapeutic and psychoeducational acting experience on the Psychopedagogical core of a higher education institution. It was observed that the relational universe that involves family dynamics of university students can exert a strong negative influence on their academic performance, causing difficulties and failures. Some of the factors of family conflict reported by students were: sibling rivalry, clear or veiled rejection of the child by the parents, parental jealousy, parental resentment about the child's achievements, excessive demands of parents as the academic success of the child, child overprotection, exaggerated sense of family responsability and loneliness in the period of adjustment to academic life. In an humanist vision, performances both psychological and psychoeducational aimed to provide an easening aid to the student, to acquire learning skills. Keywords: Family conflict. Academic performance. Psychology. Psychopedagogy. Humanism.
\end{abstract}

\section{Conflitos familiares e desempenho acadêmico numa visão humanista: relato de uma experiência}

Segundo Rogers e Kinget (1977), a teoria das relações familiares parte da proposição de que quanto mais os pais experimentam um sentimento de consideração positiva incondicional com relação ao filho, menor será a tendência do filho submeter a avaliação de sua experiência a critérios externos, mais sua experiência será guiada por um processo de avaliação organísmica e mais adequado será seu funcionamento. Na medida em que a expressão de seus sentimentos é autêntica, os pais serão capazes de apreender o ponto de referência interno de seu filho de um modo realístico e empático. De acordo com Rogers (2001), o filho deve ser tratado como uma pessoa única, digna de respeito, possuindo liberdade de avaliar sua experiência à sua maneira. Os pais devem permitir ao filho o direito de escolha autônoma, em qualquer situação na qual este se mostre capaz de suportar suas consequências, e dar ao filho uma autonomia progressiva. Também devem tentar comunicar seus sentimentos e atitudes ao filho, de um modo pelo qual ele possa entender. Dessa forma, o filho se torna continuamente consciente de muitos de seus sentimentos e dos de seus pais, se desenvolvendo adequadamente.

$\mathrm{Na}$ Terapia Centrada na Pessoa, o processo terapêutico é concebido como um fluxo experiencial, do qual participam terapeuta e cliente, numa relação intersubjetiva intencionalmente estabelecida em benefício do cliente. Atitudes de empatia, consideração positiva incondicional e congruência são vistas como necessárias e suficientes, desde que consideradas a partir do referencial de ambos os participantes da relação. 
Aspectos culturais são reconhecidos como fatores determinantes na estruturação do seting terapêutico e na viabilização da própria relação intersubjetiva. Dá-se ênfase a experienciação do cliente para possibilitar uma aprendizagem significativa que o leve a transcender seus conceitos anteriores sobre si mesmo e sobre suas relações interpessoais. A psicoterapia é vista como um tipo de relação interpessoal complexa, com objetivos definidos.

A compreensão empática, de acordo com Wood (2010), é um elemento essencial na ativação da relação intersubjetiva entre terapeuta e cliente, desde que definida como uma "co-experienciação". O conceito de empatia se refere à integração da consciência linear a uma percepção atemporal, possibilitando que o terapeuta e seu cliente compartilhem um estado especial de consciência, intencionalmente posto em ação com finalidade terapêutica. Arenúncia, por parte do terapeuta, em exercer um papel de autoridade constitui uma précondição para seu trabalho, já que no cliente está a fonte, bem como o critério, de saúde e progresso terapêutico, como decorrência da tendência à atualização inerente ao ser humano.

No acompanhamento psicopedagógico, o livre acesso discente e docente ao processo psicopedagógico permite o estabelecimento de uma comunicação efetiva, preocupada com a ação de minimizar as dificuldades de aprendizagem. A avaliação realizada através da triagem inicial possibilita o levantamento das dificuldades de aprendizagem e/ou necessidades especiais do aluno, com vistas ao seu pleno desenvolvimento. A principal preocupação é com o desenvolvimento biológico, psicológico, social e acadêmico do estudante, de forma a ajudá-lo a construir sua identidade psicossocial e profissional. É oferecido um espaço de escuta terapêutica individual ao aluno, com o objetivo de proporcionar um aprofundamento em relação ao seu autoconhecimento, para melhor compreensão de sua história pessoal, acadêmica e/ou profissional.A integração e a socialização do aluno são desenvolvidas de forma ampla, visando a sua formação ética e interpessoal. A intervenção coletiva e/ou grupal oferece momentos de reflexão social, inter e intra pessoal, ampliando a autoestima e o autoconhecimento para melhor efetividade no processo ensino-aprendizagem.

A atuação psicoterapêutica e psicopedagógica no Núcleo de Apoio Psicopedagógico (NAPp) de uma instituição de ensino superior nos possibilitou a observação de que o universo relacional que envolve a dinâmica familiar de jovens universitários pode exercer uma forte influência negativa no seu desempenho acadêmico, provocando dificuldades e insucessos, e nos levou a identificação de alguns dos fatores produtores de conflitos familiares, relatados pelos alunos, como:

1) Rivalidade entre os irmãos - quando atitudes de favoritismo dos pais por um dos filhos, provocam sentimentos de egoísmo nos filhos preteridos; a base dessa preferência pode estar nas fantasias dos pais que escolhem um descendente para concretizar seus sonhos, aspirando que seus próprios ideais de vida se realizem através dele.

2) Rejeição clara ou velada do filho pelos pais - quando a preferência por um filho leva à rejeição de outro, gerando uma relação familiar ambivalente e contraditória; impede o desenvolvimento da autoestima e da autoconfiança do filho rejeitado; e quando o filho predileto não consegue corresponder à expectativa idealizada dos pais, o "fracasso" provoca sentimentos de decepção, hostilidade e rejeição.

3) Ciúme dos pais em relação ao filho - quando há o receio de que o filho deixe de lhes manifestar afeto, trocando-o pela universidade, professores e colegas; os leva a adotar condutas agressivas ou ambivalentes em suas interações emocionais, num misto de aproximação e afastamento, com um discurso incoerente.

4) Ressentimento dos pais quanto às realizações do filho - quando o ressentimento dos pais por não terem vivido as mesmas oportunidades provoca inibição e afastamento do filho dos estudos, alimentando seus vínculos de dependência.

5) Exigência excessiva dos pais quanto ao sucesso acadêmico do filho - quando o leva a se sentir inseguro com relação à sua capacidade e maneira de ser; ele tenta engendrar uma imagem diferente daquilo que realmente é, passa a considerar que os colegas são melhores do que ele, canaliza suas energias para a sua preocupação em superá-los e fazer tudo perfeito, parecendo estar constantemente competindo e se defendendo.

6) Superproteção do filho - principalmente, quando ocorre no momento do seu ingresso na fase adulta e em relação a complexa escolha da futura carreira profissional; o impede de lutar por sua emancipação, independência e autonomia, de lidar com as situações novas e seus próprios problemas e dificuldades; tal situação se acentua, em geral, quando o aluno é oriundo de outra cidade ou de outro estado.

7) Exagerado sentimento de responsabilidade familiar do filho - quando se sente culpado pelo investimento dos pais para garantir a sua permanência na universidade, considerando sua obrigação um desempenho além do satisfatório.

8) Solidão no período de adaptação a vida acadêmica - quando não se sente preparado para enfrentar os desafios do início da sua vida na universidade, longe de casa, da família, dos pais e dos amigos, não conseguindo conciliar a vida pessoal com a vida acadêmica, o que gera sofrimento, tristeza e insegurança, podendo levar à depressão.

Nesses contextos, os conflitos familiares se tornam fatores estressores capazes de criar entraves, por vezes intransponíveis, ao aproveitamento escolar e se convertem em potentes instrumentos do fracasso 
acadêmico. Percebemos que o baixo desempenho acadêmico resultante de conflitos familiares também apresenta estreita relação com problemas emocionais e orgânicos, hábitos de estudo inadequados, falta de motivação para o estudo, dificuldades de relacionamento com professores e/ou colegas, falta de atenção às explicações dos professores, entre outros, que podem ser entendidos como maneiras destrutivas de lidar com a angústia concomitante ao estresse. Tais situações indicam a necessidade de acompanhamento e assistência.

Observamos, ainda, que as queixas mais frequentemente apresentadas pelos alunos se referem a problemas com a autoestima, acompanhados de sentimento de culpa, ansiedade e rigidez consigo mesmo e com os outros. Encontramos uma preocupação exagerada com a opinião dos outros e uma cobrança de si mesmo próxima da perfeição, para não dar margem a críticas, procurando ser "bonzinho" e "certinho" para agradar aos pais. Por vezes, o aluno deixa evidente seu sentimento de inadequação, ressentindo-se por se expor frequentemente às críticas familiares, a despeito de seus esforços para neutralizá-las com sua conduta "certinha", o que se generaliza para os seus colegas. Os alunos também referem dificuldade de dormir tranquilamente, sono agitado e interrompido durante a noite, além de problemas com a alimentação, que fica comprometida. Constatamos que alguns alunos se sentem responsáveis pela resolução dos conflitos que deixaram em casa, entre seus pais e irmãos; por outras, demonstram medo de enfrentar os pais e falar de seus próprios desejos e anseios. Sentem dificuldade de admitir sentimentos negativos e raiva contida com relação às famílias, não conseguindo expressar suas emoções, nem enfrentar as famílias sem se culpar.

De um ponto de vista humanista, a atuação, do ponto de vista psicológico, baseada na Abordagem Centrada na Pessoa, em conformidade com Wood (2010), tem partindo da crença na tendência formativa direcional, pela qual o aluno tem dentro de si amplos recursos para a autocompreensão, para alterar seu autoconceito, sua atitude básica e seu comportamento autodirigido; esses recursos podem ser mobilizados se lhe for proporcionado um clima definido de atitudes psicológicas facilitadoras, um profundo respeito por sua autonomia, dignidade e flexibilidade de pensamento e ação, com tolerância quanto às suas incertezas e ambiguidades.

E do ponto de vista psicopedagógico, a atuação tem consistido no resgate do desejo e da competência de aprender, ressaltando a importância do "aprender a aprender",redirecionandooalunoparaumaaprendizagem mais autônoma e significativa. A orientação acadêmica, de ordem organizacional, tem oportunizado espaços de concentração e memorização, a partir de uma escuta acolhedora, em situações de baixa autoestima e conflitos emocionais e/ou comportamentais. Na ação psicopedagógica, seguindo Weiss (2001), realiza-se um acompanhamento sistemático, procurando alcançar uma compreensão global da maneira como o aluno aprende, além dos desvios que estão ocorrendo nesse processo.

Entendemos que, na família, cada pessoa é uma fonte de percepções, crenças e necessidades diferentes e únicas e que essas diferenças, muitas vezes, formam as bases do conflito familiar, marcado pela maneira como o aluno estabelece suas relações com os pais, com os irmãos e outros membros da família. Assim, tem sido uma preocupação constante em nossa prática a compreensão da origem e da estrutura dos conflitos familiares, apresentados pelos alunos atendidos no NAPp, que estejam impedindo o seu bom desempenho. Procuramos facilitar ao aluno a compreensão e o encontro de uma saída para alguns dos conflitos familiares que enfrenta e para a ambivalência afetiva e emocional que está vivenciando, entre seu desejo de afirmação e crescimento e as imposições familiares.

Buscamos também facilitar seu entendimento quanto a sua insatisfação e angústia e sua aceitação quanto à necessidade de ser reconhecido e se reconhecer. Consideramos relevante que o aluno perceba a constituição de seu mundo mental, seus sonhos, expectativas e esperanças, assim como a mudança na sua estrutura defensiva, elevando seu autoconceito e the possibilitando sentir as pessoas como menos ameaçadoras, para que possa pensar, compreender e reagir positivamente às suas circunstâncias de vida, tanto familiares quanto acadêmicas, tornando-se mais feliz.

Objetivando o funcionamento pleno do aluno enquanto pessoa, procuramos facilitar o reconhecimento de sua capacidade de processar os estímulos sem distorcê-los por mecanismos defensivos e sua abertura à experiência, com sua personalidade e seu self continuamente em fluxo, agindo de acordo com o que sente em cada momento e confiando em seu organismo para encontrar o comportamento mais satisfatório para cada situação existencial. Enfim, objetivamos auxiliar o aluno no processo de trazer à tona o melhor de si mesmo, no sentido de melhorar sua vida.

\section{Referências}

ROGERS, C. R. (2001) Sobre o poder pessoal. São Paulo: Martins Fontes.

ROGERS, C. R.; KINGET, G. M. (1977) Psicoterapia e relações humanas: teoria e prática da terapia não-diretiva. Belo Horizonte: Interlivros.

WEISS, M. L. L. (2001) Psicopedagogia clínica: uma visão diagnóstica dos problemas de aprendizagem escolar. 8. ed. Rio de Janeiro: DP\&A.

WOOD, J. K. (org.) (2010) A abordagem centrada na pessoa. 5. ed. Vitória, ES: Editora EDUFES 